\title{
Epidemiological Aspects of Infectious Conjunctivitis
}

\author{
Herlinda Mejía-López ${ }^{1}$, Carlos Alberto Pantoja-Meléndez², \\ Alejandro Climent-Flores ${ }^{1}$ and Victor M. Bautista-de Lucio ${ }^{1}$ \\ IInstitute of Ophthalmology "Fundación Conde de Valenciana" I.A.P. \\ Research Unit, Mexico City \\ ${ }^{2}$ Faculty of Medicine, National Autonomous University of Mexico \\ Public Health Dept. \\ Mexico
}

\section{Introduction}

Conjunctivitis can be broadly classified into two groups, infectious and noninfectious. Infectious conjunctivitis is mainly caused by bacteria $(60 \%)$, followed by viruses $(20 \%)$, with the remaining cases caused by Chlamydia, fungi and parasites. Infectious conjunctivitis tends to present during the summer months.

Non-infectious conjunctivitis includes allergic causes, often during the flowering period in spring. However, nosocomial outbreaks and work related conditions, as well as mechanical and functional causes are not associated with any particular time of year.

Conjunctivitis can also be divided into epidemic and non-epidemic, associated with risk factors, immunological factors, and mechanical-functional causes. This classification allows professionals to tailor patient care more effectively.

\subsection{Epidemic conjunctivitis}

There are several pathogens reported to be able to affect large groups and cause greater or wider than expected epidemics. However, conjunctivitis has caused several epidemics in the past and although most cases are benign and self-limiting, many underestimate its impact on the population and its ability to spread rapidly.

Epidemic types of conjunctivitis, especially hemorrhagic types, are subject to surveillance by world health systems. They are more common in the summer and one of their main features is the rapid spread and numbers of cases that occur in short periods of time. Some serotypes are widely distributed, and these are usually those which show this epidemic capability. ${ }^{1,2}$ Conjunctivitis can be transmitted efficiently by virtually all known methods of transmission (see Modes of transmission), which partly explains the rapidity of its spread.

It is known that acute hemorrhagic conjunctivitis occurs in tropical areas due to high temperatures and high relative humidity, which prolongs the survival of viruses. Other viral intrinsic factors, such as in adenovirus, allow viral establishment in adverse environments, and these factors are associated with epidemics. It is increasingly becoming clear that medical staff also participate in the spread of an epidemic, as the handling of patients without appropriate risk management can make medical personnel a disease vector. 
Cases of epidemic hemorrhagic conjunctivitis are mainly caused by adenovirus. However, coxsackie A24 is currently responsible for the reported worldwide epidemic. It was first identified in Ghana in 1969, later spread to Asia and Oceania, and at the end of the twentieth century regular reports of events caused by several strains of coxsackievirus had been published. ${ }^{3-9}$ This epidemic affected several countries in all continents including Australia, where an acute conjunctivitis caused by coxsackie A24 in a non-.hemorrhagic form was identified. ${ }^{10-12}$ (Figure 1).

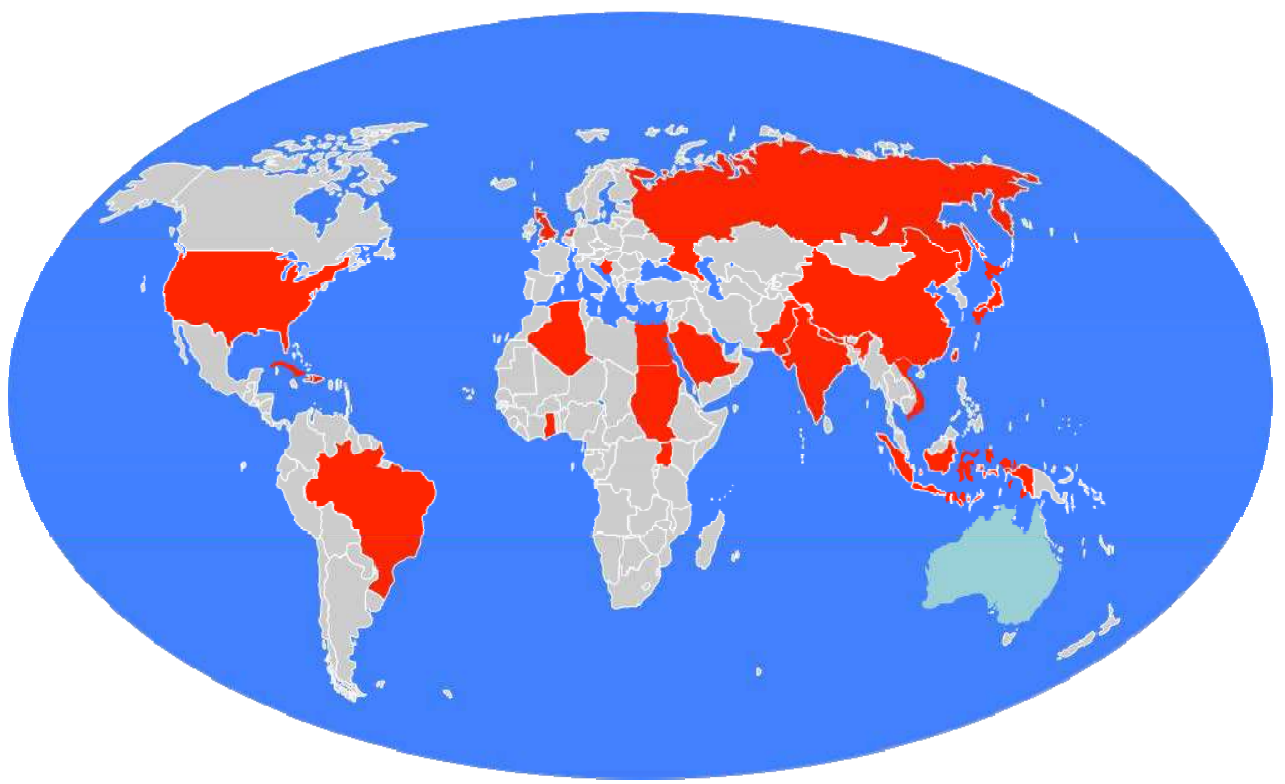

Fig. 1. Distribution of epidemic hemorrhagic conjunctivitis caused by coxsackie A24. In red, countries that presented with hemorrhagic conjunctivitis; in blue, countries that presented with non-hemorrhagic conjunctivitis.

\subsection{Non-epidemic conjunctivitis}

Conjunctivitis is a disease that represents a significant proportion of ophthalmologist consultations. Usually, non-epidemic forms of this condition do not have the potential to affect large populations, but its impact is on medical spending, temporary disability and in rare cases, steps to contain a possible outbreak.

The main cause of non-epidemic conjunctivitis is allergic conjunctivitis. As a group, they represent the main reason for consultation for conjunctivitis in developed countries and have also shown an increase in prevalence and incidence.

Allergic conjunctivitis is a very common disorder in adults as well as in children. The estimations of its incidence, reported in the literature, vary from 15 to $25 \%$ of the general population. ${ }^{13}$

Allergic conjunctivitis includes 5 clinical entities (classes), such as Seasonal Allergic Conjunctivitis (SAC), occurring most frequently, followed by Atopic Keratoconjunctivitis (AKC), Vernal Keratoconjunctivitis (VKC), Perennial Allergic Conjunctivitis (PAC) and 
Giant Papillary Conjunctivitis (GPC). The SAC and PAC occur in relatively mild forms, while VKC and AKC, in which also cornea is affected, and represent more severe, often bilateral, forms. The GPC appears only sporadically. ${ }^{14}$

Allergic conjunctivitis is associated with common allergens; is common to find that sufferers also have atopy and a family history of allergy. This type of conjunctivitis occurs most often between 10 and 40 years of life, peaking in the second decade.

The most frequently involved allergens are: I. Various inhalant allergens, such as pollen species, Dermatophagoides pteronyssinus, Dermatophagoides farinae, various moulds (Aspergillus fumigatus, Aspergillus niger, Alternaria family, Cladosporium family, Penicillium family, Candida albicans, Thermopolyspora polyspora), animal danders (hairs, feathers, squamae), organic dusts, some foods in powder form (flour kinds, spices); II. Some drugs (e.g. in powder form, ointments, etc); III. Digested foods; IV. Contact allergens. ${ }^{15}$

Some cases of conjunctivitis are associated with chemical or physical agents inherent in patients' work conditions and occupational hazards. Among these chemicals, the most common causes of work-related conjunctivitis are mepacrine, ammonia and vanadium, mainly linked to the metalworking industry. In the case of physical agents, ultraviolet light received in outdoor occupations such as police and construction work is the main cause of conjunctivitis.

Another type of occupational hazard associated with conjunctivitis is the handling of infected secretions. This can present a high risk to medical staff that provides care to patients if appropriate hygiene measures are not taken.

The remaining conjunctivitis cases can be attributed to bacteria, parasites, fungi and viruses (non-epidemic serotypes), which are also an important cause of daily ophthalmic consultations. However, these should be tackled depending on the causative factor. These types of conjunctivitis can be considered as nosocomial outbreaks, as they are mainly acquired in hospitals (e.g. Staphylococcus sp., adenovirus, herpes virus and Candida spp., among others).

\section{Risk factors}

\subsection{Environmental risk factors, host susceptibility and pathogen factors}

Conjunctivitis is not distributed randomly; cases manifest when increasing risk factors converge. Like other diseases that affect humans, it occurs on the conjunction of three factors: the causative agent, the environment and host specific factors.

Allergic conjunctivitis requires both a significant interaction of the environment and the individual's susceptibility to develop allergic conditions. The major known risk factors are a history of asthma or multiple allergies, smoking, contact lenses and environmental pollution. ${ }^{13}$ On the other hand, infectious conjunctivitis depends on the specific capabilities of the infective agent, though the human factor is also important as humans can often act as a disease reservoir.

Theoretically, we are all susceptible to conjunctivitis, but its presentation may depend more on risks associated with patient contact or contaminated materials. It has, however, been observed that age and sex are important factors, with children, young adults and women being the main groups affected.

There are 2 basic forms of allergic conjunctivitis with respect to the localization of the initial allergic reaction (antigen-antibody or antigen-sensitized Th1-cells interaction with subsequent steps). In the primary form of allergic conjunctivitis, the allergic reaction, due to direct 
exposure of Conjunctiva to an external allergen, occurs in the conjunctival mucosa. In this case, the conjunctiva is the primary and solely site of the allergic reaction with all subsequent steps, resulting in the development of the primary (classical) form of allergic conjunctivitis. In the secondary form of allergic conjunctivitis, the initial allergic reaction takes place in other (related) organ, mostly in the nasal mucosa, due to the direct exposure of nasal mucosa to an external allergen, leading to release of various factors (mediators, cytokines, chemokines and other factors), which can then reach conjunctiva by various ways, such as lacrimal system, blood, lymphatic or neurogenic network, and induce there the secondary conjunctival response (secondarily induced allergic conjunctivitis). In principle, all five clinical classes of allergic conjunctivitis can occur either in a primary or in a secondary form. ${ }^{14,16}$

Various hypersensitivity (immunologic) mechanisms can be involved in all five clinical classes of allergic conjunctivitis, both in their primary and in their secondary forms. The immediate (IgE-mediated) hypersensitivity mechanism, upon participation of the IgE antibodies, mast cells, eosinophils, epithelial cells and Th2-cells also designated as atopy, having been often studied and well documented, has been confirmed as the most frequent mechanism underlying the allergic conjunctivitis.

However, the evidence for involvement and causal role of other so-called non-immediate (non-IgE-mediated) hypersensitivity mechanisms, such as late (Type III) and delayed (Type $\mathrm{IV}$, cell-mediated) in the allergic conjunctivitis of all five classes, is growing and became to be recognized.17-19 The existence of the primary and secondary form of the allergic conjunctivitis as well as particular types of conjunctival response can only be demonstrated by provocation tests with allergen.

The conjunctival provocation tests with allergen confirm the primary allergic conjunctivitis form, whereas the nasal provocation tests with allergen upon monitoring of objective conjunctival signs and subjective symptoms confirm the secondary (secondarily induced) conjunctivitis form. Patients with both the forms of allergic conjunctivitis can develop various types of conjunctival response to allergen challenge, such as immediate (early), late or delayed response, depending on the type of hypersensitivity mechanism(s) involved.19-21

\subsection{Immune response and risk factors}

Epidemic keratoconjunctivitis caused by adenovirus induces a strong acute inflammatory response. Efforts have been made to identify host factors that promote and influence the severity of the clinical picture, with the purpose of generating an idea of prognosis. Among the factors to be studied, the immune response is important, as this may influence the damage done by the disease. The mechanisms that decide the initial response of the host depends on the innate immune response mediated by proinflammatory cytokines. These are essential in establishing the adaptive immune response, which provides long term protection.

Recently, the study of receptors in the cells involved with the innate immune response has received particular attention. The early interactions between pathogens and host cells are critical in the establishment of the infection. These receptors, known as Pattern Recognition Receptors (PRRs), recognize molecular patterns of pathogens (PAMP) that are highly conserved, and manage the effectiveness of the adaptive immune response that may limit or exacerbate the infection. ${ }^{22}$ It has been shown that human Toll-like receptors (TLRs) play an essential role in triggering the innate immune response, recognizing a variety of PAMPs associated with bacteria, viruses, protozoa and fungi. The signals initiated by the interaction of TLRs with specific antigen ligands direct the inflammatory response, which attempts to eliminate the pathogen and start the adaptive response. In humans, eleven TLRs have been identified (TLR1-TLR11). ${ }^{22,23}$ 
The TLR2 receptor is particularly important, as it has a unique mechanism of ligand recognition where it cooperates with other TLR family members, particularly TLR1 and TLR6. ${ }^{24}$ There are several studies showing that herpes simplex virus type 1 (HSV1), type 2 (HSV2), cytomegalovirus (CMV) and respiratory syncytial virus (RSV) induce TLR2dependent proinflammatory cytokines in an attempt to induce cell protection. ${ }^{25-27}$

On the other hand, single nucleotide polymorphisms (SNPs) in genes encoding TLRs have also been reported. The TLR2 Arg677Trp and Arg753Gln SNPs are associated with susceptibility and severity of viral infections. ${ }^{25-28}$ In our laboratory we found the Phe707Phe polymorphism in the Mexican population, with an allelic frequency of $7.5 \%$ and this suggests that this SNP not affect our population..$^{29}$

The first line of defense against viruses is interferons. However, proinflammatory cytokines and antimicrobial peptides also promote the cell-mediated immune response, which is essential for the resolution of infection. ${ }^{30}$ Beta-defensins (HBDs) act as antimicrobial peptides in humans and are also effective against a variety of microorganisms. ${ }^{31}$

In immunoprivileged tissue such as the cornea, the complex mechanisms that prevent the induction of inflammation and the behavior of cytokines and peptides of the innate immune response must be tightly regulated. An infection may then upset this microenvironment and cause damage to the ocular surface. Adenovirus infections induce expression of IP-10 and I-TAC, defense peptides against Ad5 and Ad3 respectively. It is suggested that epidemic strains of adenovirus (Ad8 and Ad19) could be resistant to these defensins. Interestingly, HBDs have also been suggested to possess an additional protective effect that contributes to the corneal healing process. ${ }^{32,33}$

Genetic variants at the promoter region of the beta defensin-1 (DEFB-1) gene are uncommon, however recent reports showed three SNPs that affect gene expression. ${ }^{34,35}$ These $-20 \mathrm{~A} /-44 \mathrm{C} /-52 \mathrm{G}$ haplotypes have all been associated with chronic lung infection with P. aeruginosa. ${ }^{36}$ The $-44 \mathrm{C}$ allele also predisposes to infection by HIV37,38 and Candida spp. ${ }^{39}$ Moreover, Carter et al also found that it strongly associated with endophthalmitis. ${ }^{40}$ In a recent study in our laboratory, we found a significantly higher frequency of $-44 \mathrm{C}$ and $-52 \mathrm{G}$ DEFB-1 polymorphisms in a cohort of 30 samples taken from patients with adenovirus infection. These showed an increased risk of infection of 2.86 for $-44 \mathrm{C}$ allele and 2.44 for allele $-52 \mathrm{G}$. These findings indicate that genotypes $-44 \mathrm{C} / \mathrm{G}$ and $-52 \mathrm{G} / \mathrm{G}$ may be associated with adenovirus infection (data not reported). The results obtained in the works above represent preliminary studies that require analysis of larger populations worldwide to determine whether these polymorphisms can be used as marker of infection susceptibility.

\section{Transmission}

Infectious conjunctivitis has a transmission capability dependant on the etiological agent involved.

Bacterial conjunctivitis is highly contagious and is associated with close contact between patients, a situation common in kindergartens and childcare. This predisposes to constant outbreaks, but these are rarely identified as children gradually leave the disease area.

Viruses, particularly respiratory adenovirus, which produces pharingoconjunctivitis also have a high capability of infection and is often confused with Streptococcus pneumoniae.

Fungi have a low transmission capability, but can be transmitted more efficiently amongst the sick or immunocompromised. 


\section{Forms of transmission}

Conjunctivitis is most commonly transmitted by direct contact with secretions from a sick patient. However, air droplet transmission is also common, as well as via vehicles such as Hyppelates spp., which act as a vector for bacterial transmission.

\subsection{Contact transfer}

Transmission by contact with a contaminated body surface is the usual transfer mechanism for staphylococci, streptococci and enterobacteria. This is also the classic mechanism of transmission of nosocomial infections. Hand washing and use of protective barriers such as gloves and lab coats are sufficient to prevent transmission, as well as changing the dose of medication. Despite the fact that protective measures are simple, compliance is difficult and may become costly. However, contact transmission is responsible for a large proportion of cases, which implies that control of basic hygiene may reduce the case load significantly.

\subsection{Droplet transmission}

This transmission occurs through close contact with a patient. The droplets have a diameter greater than $5 \mu \mathrm{m}$ and are generated by coughing, sneezing, talking and during certain health care procedures.

Transmission occurs when droplets are deposited on the Conjunctiva or nasal mucosa of a susceptible host. The droplets travel an average distance of one meter from the patient and quickly fall to the ground. Therefore, transmission does not occur at greater distances and drops are not kept in the air for long periods, so special air handling is not required to prevent transmission by this mechanism.

\subsection{Air transmission}

This occurs through close or medium range contact with a patient. The droplets in this case have a diameter less than $5 \mu \mathrm{m}$ and are generated from an infected person during breathing, speech, coughing and sneezing.

Transmission occurs when microorganisms containing droplets generated by an infected person dry and remain airborne for long periods of time. These organisms (usually viruses) can be dispersed widely by air currents and inhaled by a susceptible host within the same room or even at distance depending on environmental factors, so in this case air handling and ventilation are important to prevent contagion. This type of transmission is less common but control is more expensive and complex.

\subsection{Transmission by vectors}

Transmission by vector is not considered widely relevant, but it is well known that Chlamydia can be transmitted by flies.

In the case of trachoma, which starts as a follicular conjunctivitis, it has been documented that the housefly (Hyppelates spp.) facilitates the transfer of infected secretions from patients to others.

\section{Outbreaks}

Conjunctivitis has high potential for nosocomial outbreaks depending on the causative agent, and has the capability to affect a large number of people. One of the most important 
features of these outbreaks is the speed of propagation, but with the appearance of a benign condition. Its importance lies in allowing us a panoramic view of the strengths and weaknesses of the systems of epidemiological surveillance in hospitals.

\subsection{Microorganisms involved in outbreaks}

\subsubsection{Bacterial}

\subsubsection{Acute infections}

The most common outbreaks are produced by Staphylococcus spp., Streptococcus spp., and Haemophilus sp. Some patients may be positive in culture for Pneumococcus sp.

Crum et al. described an outbreak of Streptococcus pneumoniae in 92 of 3500 soldiers. ${ }^{41}$ Martin et al also reported an outbreak affecting 698 college students with this organism. ${ }^{42}$ In another report, Haemophilus influenzae was shown to be responsible for 428 cases in Israel. 43

\subsubsection{Hyperacute infections}

Hyperacute bacterial conjunctivitis is most frequently caused by Neisseria gonorrhoeae, related to oculopharingeal disorders in neonates and in sexually active young people. In 1987 and 1988, there were over 9,000 cases of conjunctivitis caused by N. gonorrhoeae in Ethiopia and children under 5 years were the group primarily affected. ${ }^{44}$ The aboriginal population of central Australia has also has been frequently affected, with 447 cases reported in 1997.45

\subsubsection{Chronic infections}

Staphylococcus aureus is the bacteria most commonly reported in the literature as causing chronic conjunctivitis.

\subsubsection{Chlamydial conjunctivitis}

Conjunctivitis is considered chronic after 4 weeks and the best known cases of chronic follicular conjunctivitis are caused by Chlamydia trachomatis. This bacterium also causes cervicitis in women and urethritis and epididymitis in men. Unfortunately, these clinical manifestations may occur as subclinical infections, preventing the detection of the bacteria.

The newborn of women carrying Chlamydia trachomatis have a high incidence of conjunctivitis and pneumonia. In adults, conjunctivitis appears to be transmitted primarily by contact with infected genital discharge and usually occurs as isolated individual episodes, with few progressing to eye symptoms. ${ }^{46,47}$

On the other hand, in areas endemic for trachoma the first contact with $C$. trachomatis is related to the prevalence of infection in the community. Trachoma is clinically characterized by the presence of papillae and follicular inflammation of the tarsal conjunctiva and is referred to as active trachoma. ${ }^{48}$ Trachoma can be produced by serovars A-C (A, B, Ba and C) of C. trachomatis and is endemic in 55 countries around the world. ${ }^{49}$ Serovars D-K (genitals) may also affect the neonatal conjunctiva. It has also been reported that the species Chlamydophila pneumoniae and Chlamydophila psittaci may also cause trachoma, and may cause polyinfection with $C$. trachomatis. ${ }^{50}$ However, as trachoma is a chronic infection, it does not usually cause epidemics.

\subsubsection{Viral infections}

Viruses are the principal cause of conjunctivitis worldwide, with adenovirus and coxsackievirus being the most frequent. It is reported that follicular conjunctivitis can occur as part of the pharyn $x$ and respiratory syndrome, or as a separate entity. 


\subsubsection{Pharyingoconjunctival fever caused by adenovirus}

This disease is often accompanied by lymphadenopathy and most commonly associated with genotypes of the subgenera B and E (Ad3, Ad7 and Ad4). ${ }^{51-53}$

\subsubsection{Epidemic keratoconjunctivitis}

This severe form of conjunctivitis caused by adenovirus can incapacitate the patient for several weeks. The aftermath of the infection can leave subepithelial infiltrates that may affect the visual field. Outbreaks are caused by subgenus D (AD8, and AD37 Ad19).54,55

\subsubsection{Acute hemorrhagic conjunctivitis}

The coxsackieviruses, which are subtypes of enterovirus from the family Picornaviridae are usually responsible for this infection. (See Epidemic conjunctivitis). The greatest number of reports of conjunctivitis worldwide is shown on this webpage (http://www.promedmail.org). This page shows that since 2003, coxsackievirus A24 has been responsible for most outbreaks, followed by avian influenza conjunctivitis (H1N1).

\subsubsection{Herpes conjunctivitis}

Herpes (HSV) conjunctivitis produces insidious and recurrent forms, and therefore can be very difficult to eradicate. HSV1 causes the typical forms of herpetic keratitis but HSV2 conjunctivitis has also been reported in infants or adults with sexual herpes. In 1989, an outbreak of HSV1 in a school population in Minneapolis in Minnesota, USA affected 175 children, of which HSV1 was isolated in 35\%. ${ }^{56}$

\subsection{Prevention and control of outbreaks}

Prevention and control of outbreaks of conjunctivitis are subject to support by the work in hospitals, community and laboratories.

Initially, it is essential to have a formal or informal surveillance (epidemiological work) to monitor infections that can commonly affect the health of a group. For example, causes of hemorrhagic conjunctivitis are subject to surveillance by national health systems of many countries.

One of the most important components in the presentation of any outbreak is medical and nursing staff who may become a source of contagion. This failure is due to widespread use of antibiotics and insufficient cleaning of surfaces and equipment due to reduced vigilance by medical staff and unsafe risk management. Hence, the use of preventive measures is necessary to cut the chain of transmission. Contact isolation is also critical to preventing outbreaks in institutions and should be strictly executed.

During epidemics, emphasis should be put on preventing the spread of infection, which is achieved by careful hand washing, cleaning and meticulous handling of objects that have been in contact with eye or respiratory secretions. It is also critical to consider that patients are contagious until the symptoms disappear completely.

The following is highly recommended:

- Wash hands immediately after treating or handling secretions from a patient diagnosed with probable or confirmed conjunctivitis. Hand washing should be performed even when latex gloves were used.

- Use gloves and lab coat if in contact with a patient or their body fluids.

- Use of personal protective measures when conducting procedures that may generate splashes to mucous membranes of the staff.

- Restrict access of health staff only to those who have direct patient responsibility. 
- Medical equipment (apparatus and instruments) as well as chairs and tables of should be scrupulously disinfected to prevent contamination of other patients and/or health personnel.

- Patients should be isolated or grouped with other patients with an active infection with the same pathogen. It is important to restrict access to family, particularly in the case of neonates, infants or immunocompromised individuals. The material used with patients should be disposable equipment, or if that is not possible the equipment should be disinfected.

\subsection{Outbreak vigilance}

Preventive measures have the effect of decreasing the frequency and severity of outbreaks, however, personnel should be prepared to efficiently deal with them should they arise.

It is necessary to follow a methodology to reach containment of the outbreak to contain the damage to the population by: identifying risk factors, controlling sources of infection, implementation of interventions to prevent additional cases and breaking the chain of transmission.

The outbreak vigilance involves four phases (Figure 2):

i. Knowledge of the problem

ii. Critical phase (decision making)

iii. Care phase

iv. Resolution phase

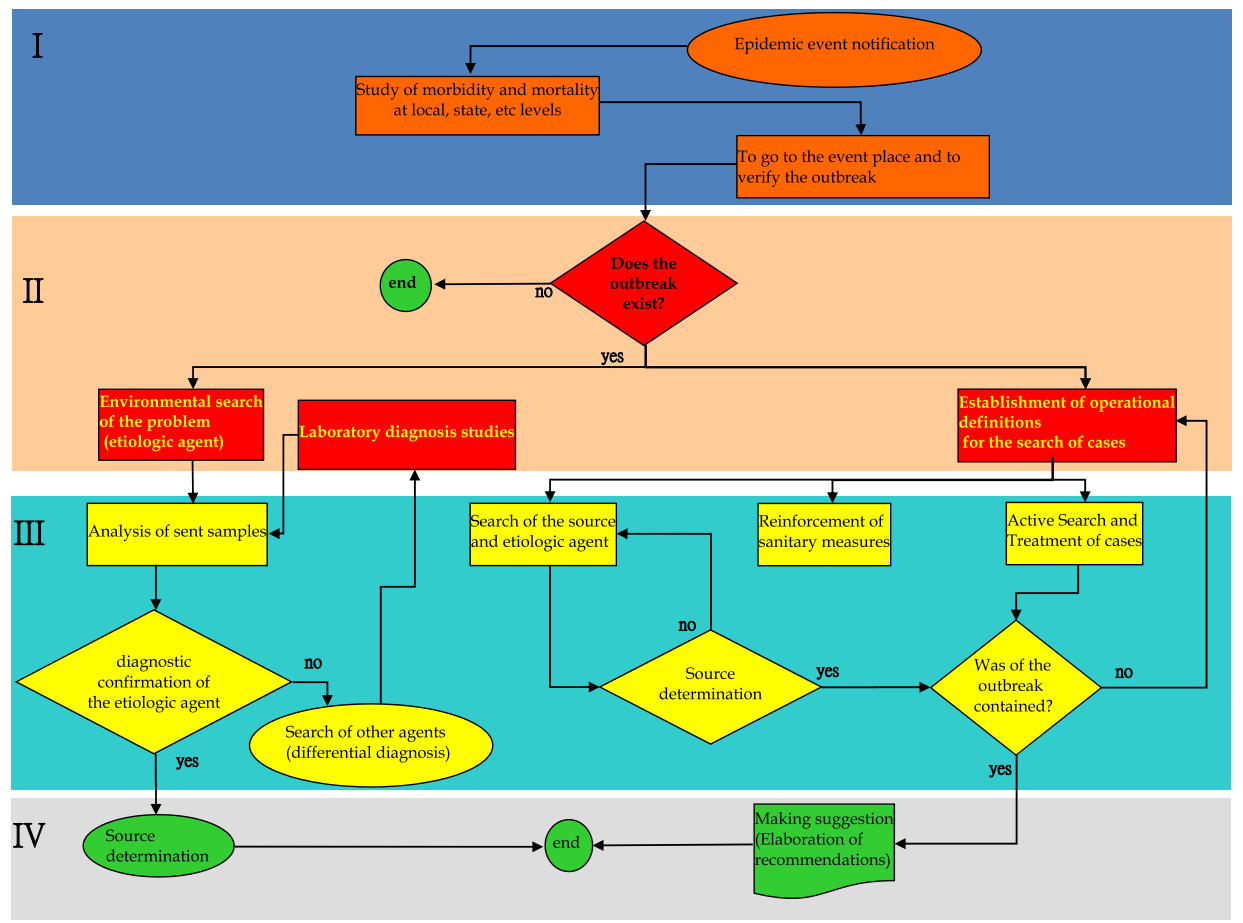

Fig. 2. Outbreak vigilance algorithm: I) Knowledge of the problem, II) Decision making, III) Attention of the outbreak and IV) Problem resolution. 
Stage I requires detection of conjunctivitis cases and confirmation either in the hospital or the community. In Stage II, decisions are made to deal with extreme conditions and guide further action. The critical phase is essential, as it is necessary to react to suspected cases and identify the infectious agent in order that efficient control measures can be undertaken. This also allows the search for the pathogen in the environment or community (particularly in cases with contact transmission), as well as establishment of accurate diagnostic tests. ${ }^{57-61}$

\subsection{Laboratory assays}

The clinical manifestations of conjunctivitis suggest the possible etiology of infection, but the diagnosis should be confirmed by laboratory testing.

The type of inflammatory response (papillary, follicular, membranous, pseudomembranous or ulcerative granulomatous), time of onset, intensity and duration of inflammation (acute or chronic), type of discharge (mucoid, purulent or watery) and associated symptoms (itching, foreign body sensation) should be carefully evaluated and taken into consideration to establish a presumptive diagnosis.

Generally, bacterial conjunctivitis presents with diffusing conjunctival injection, conjunctival chemosis, papillary hypertrophy (in areas of conjunctiva firmly attached, such as the tarsus and semilunar fold) and purulent discharge.

The most frequent causative organisms with this pathology are Staphylococcus spp, Neisseria gonorrhoeae or N. meningitidis, Streptococcus pneumoniae, Pseudomonas aeruginosa or Escherichia coli.

Follicular conjunctivitis is characterized by tearing, mucopurulent discharge, redness, conjunctival follicles and cellular infiltration. It can be diagnosed as acute or chronic according to onset and duration of inflammation. Causes of acute follicular conjunctivitis include: acute adenovirus infection (pharyngoconjunctival fever), epidemic keratoconjunctivitis, herpes simplex, varicella zoster, and viral influenza. In contrast, chronic cases are caused by Chlamydia spp., toxic follicular conjunctivitis (molluscum contagiosum of lid margin, response to topical medications), Moraxella spp. and Actinomyces israelli (infection of the canaliculus).

The clinical diagnosis of conjunctivitis can be confirmed by several techniques based on microbiological examination of ocular samples. There are often two difficulties in identification and microbiological diagnosis in ocular infections. The first is the small amount of sample obtained from the eye; the second is the need to obtain a result in a short time to give timely treatment to the patient.

Tests performed for the identification of microorganisms in eye infections include classic microbiological tests, such as stains and cultures, as well as the use of molecular techniques such as real-time PCR. Both types of methodology are suitable for the identification of infectious organisms; however, they both have advantages and disadvantages. The classic tests can identify infectious organisms with near certainty, but can take a long time. Realtime PCR offers results in a short time, as well as high sensitivity, but has high costs and not all hospitals are able to offer this test routinely.

Based on our experience, we developed an algorithm for identification of microorganisms that cause conjunctivitis (Figure 3). Here we show how a presumptive clinical diagnosis is confirmed by real-time PCR.

Molecular techniques to identify microorganisms at species level allow tailoring of therapy to the etiological agent. On the other hand, the use of microbiological culture is not ruled out completely, as these can be used for confirmatory studies. Automated sequencing of $16 \mathrm{~S}$ ribosomal genes to identify bacterial species may also be important for epidemiological studies. 


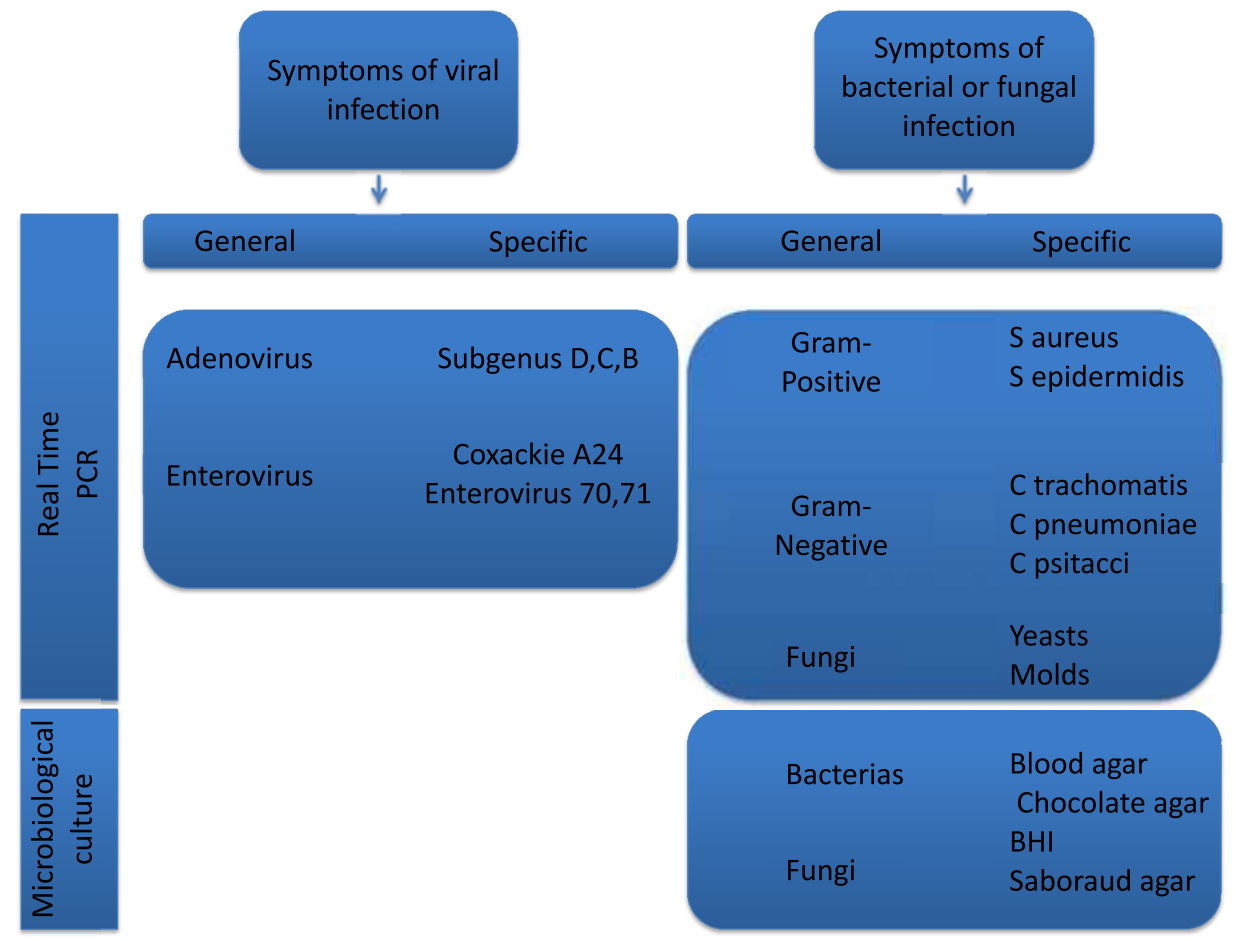

Fig. 3. Algorithm for identification of the causative agent of conjunctivitis.

\subsection{Knowledge phase}

- Formal notification sources: Weekly reporting of new cases, cases with poor outcomes, case study reporting, etc.

- Informal notification sources: Radio, television and other communication media.

- Comparison of the observed and expected incidence, mortality and morbidity statistics from affected area, as well as national and international spread.

- Information gathering: go to the affected area to verify the existence of outbreak.

- Confirm the diagnosis to ensure that the problem has been properly assessed (medical and laboratory assessment etc.).

- Association of two or more cases in time, place and person.

- Verify the presence or not of "artifacts" that could give false positive or negatives (intentional awareness campaigns, changes in case definition, implementation of new diagnostic tests, etc.).

- Standardize criteria for deciding the criteria for determining if a suspected patient is involved in the outbreak.

- Construct an operational definition of a case with:

- Syndromic approach

- Simple and clear

- Broad enough to include all cases (sensitive) but restricted enough to capture only the affected group (specific). 


\subsection{Critical phase}

- Know the number of cases treated or untreated by health staff (especially in community cases where there are other forms of health care).

- Give immediate attention to reducing the impact of the disease in the population.

- $\quad$ Strengthen health measures.

- Conduct a syndromic approach.

- Focus on known risk factors with measures to cut the chain of transmission.

- Carry out bacteriological control (if necessary).

- Determine and characterize the source of the outbreak.

- Common

- Propagated

- $\quad$ Mixed

- Search the environment for propagating agents.

- Apply diagnostic battery for potential agents.

- Differential diagnosis.

- Analysis of environmental samples.

\subsection{Resolution phase}

This stage should give health advice to reduce the risk of affecting a larger population, and this should be tailored to the source, mode of transmission and exposure duration.

\section{Conclusions}

Conjunctivitis is one of the most common infections worldwide, which is associated with its significant potential for infection and spread as well as human factors that govern inherent susceptibility to infection.

Infectious conjunctivitis is responsible for many nosocomial and community outbreaks, as it may be transmitted by virtually all known routes. It is also responsible for epidemics and pandemics, such as the current hemorrhagic conjunctivitis outbreak caused by coxsackie A24.

Conjunctivitis, like many conditions, is not randomly distributed and requires a convergence of risk factors: genetic, immunological, environmental and pathogen-related. These risk factors are very broad in the case of conjunctivitis and there is the additional complication of fly vector transmission of trachoma and follicular conjunctivitis.

Epidemiological knowledge of conjunctivitis allows us to identify and react promptly to control outbreaks based on the determination of the source and the re-establishment of sanitary measures and basic hygiene.

\section{Acknowledgements}

We acknowledge the Institute of Ophthalmology "Fundación Conde de Valenciana" IAP for sponsoring this chapter and QBP Diana Gabriela Ponce Angulo, for his technical contributions to this paper. This work was support partially by CONACyT-126779.

\section{References}

[1] Moura, F. E., Ribeiro, D. C., Gurgel, N, da Silva Mendes, A. C., Tavares, F. N., Timóteo, C. N. and daSilva, E. E. (2006). Acute haemorrhagic conjunctivitis outbreak in the city of Fortaleza, northeast Brazil. Br J Ophthalmol, 90, 1091-1093. 
[2] Wright, P. W., Strauss, G. H. and Langford, M. P. (1992). Acute hemorrhagic conjunctivitis. Am Fam Physician, 45, 173-178.

[3] Cabrerizo, M., Echevarria, J. E., Otero, A., Lucas, P. and Trallero, G. (2008). Molecular characterization of a coxsackievirus A24 variant that caused an outbreak of acute haemorrhagic conjunctivitis in Spain. J Clin Virol, 43, 323-327.

[4] Jun, E. J., Nam, Y. R., Ahn, J., Tchah, H., Joo, C. H., Jee, Y., Kim, Y. K. and Lee, H. (2008). Antiviral potency of a siRNA targeting a conserved region of coxsackievirus A24. Biochem Biophys Res Commun, 376, 389-394.

[5] Katiyar, B. C., Misra, S., Singh, R. B. and Singh, A. K. (1981). Neurological syndromes after acute epidemic conjunctivitis. The Lancet, 318, 866-867.

[6] Khan, A., Sharif, S., Shaukat, S., Khan S. and Zaidi, S. (2008). An outbreak of acute hemorrhagic conjunctivitis (AHC) caused by coxsackievirus A24 variant in Pakistan. Virus Res, 137, 150-152.

[7] Oberste, M. S., Maher, K., Kilpatrick, D. R., Flemister, M. R., Brown, B. A. and Pallansch, M. A. (1999). Typing of human enteroviruses by partial sequencing of VP1. J Clin Microbiol, 37, 1288-1293.

[8] Park, S. W., Lee, C. S., Jang, H. C., Kim, E. C., Oh, M. D. and Choe, K. W. (2005). Rapid identification of the Coxsackievirus A24 variant by molecular serotyping in an outbreak of acute hemorrhagic conjunctivitis. J Clin Microbiol, 43, 1069-1071.

[9] Wu, D., Ke, C. W., Mo, Y. L., Sun, L. M., Li, H., Chen, Q. X., Zou, L. R., Fang, L., Huang, P. and Zhen, H. Y. (2008). Multiple outbreaks of acute hemorrhagic conjunctivitis due to a variant of Coxsackievirus A24: Guangdong. J Med Virol, 80, 1762-1768.

[10] Goh, K. T., Ooi, P. L., Miyamura, K., Ogino, T. and Yamazaki, S. (1990). Acute haemorrhagic conjunctivitis: seroepidemiology of coxsackievirus A24 variant and enterovirus 70 in Singapore. J Med Virol, 31, 245-247.

[11] Lim, K. H., \& Yin-Murphy, M. (1971). An epidemic of conjunctivitis in Singapore in 1970. Singap Med J, 12, 247-249.

[12] Oh, M., Park, S., Choi, Y., Kim, H., Lee, K., Park, W., Yoo, Y., Kim, E. and Choe, K. (2003). Acute hemorrhagic conjunctivitis caused by coxsackievirus A24 variant. Emerg Infect Dis, 9, 1010-1012.

[13] Bielory, L. (2008). Ocular allergy overview. Immunol Allergy Clin North Am, 29, 1-23.

[14] Pelikan, Z. (2009). Seasonal and perennial allergic conjunctivitis:the possible role of nasal allergy. Clin Exp Ophthalmol, 37, 448-457.

[15] Pelikan, Z. (2009). The possible involvement of nasal allergy in allergic keratoconjunctivitis. Eye, 23, 1653-1660.

[16] Bacon, A. S., Ahluwalia, P., Irani, A. M., Schwartz, L. B., Holgate, S. T., Church, M. K. and McGill, J. L. (2000). Tear and Conjunctival changes during the allergen-induced early- and late-phase responses. J Allergy Clin Immunol, 106, 948-954.

[17] Anderson, D. F. (1996). The conjunctival late-phase reaction and allergen provocation in the eye. Clin Exp Allergy, 26, 1105-1111.

[18] Pelikan, Z. (2010). Allergic conjunctivitis and nasal allergy. Curr Allergy Asthma Rep, 10, 295-302.

[19] Calder, V. L. (2002). Cellular mechanisms of chronic cell-mediated allergic conjunctivitis. Clin Exp Allergy, 8, 814-817. 
[20] Leonardi, A., Fregona, I. A., Plebani, M., Secchi, A. G. and Calder, V. L. (2006). The1and Th2-type cytokines in chronic ocular allergy. Graefe's Arch Clin Exp Ophthalmol, $244,1240-1245$.

[21] Bielory, L. and Friedlaender, M. H. (2008). Allergic conjunctivitis. Immunol Allergy Clin North $A m, 28,43-57$.

[22] Sandor, F. and Buc, M. (2005). Toll like receptors. I Structure function and their ligands. Folia Biologica (Praha), 51, 148-156.

[23] Du, X., Poltorak, A., Wei, Y. and Beautler, B. (2000). Tree novel mammalian toll-like receptor: gene structure, expression and evolution. Eur Cytokine Netw, 11, 362-371.

[24] Hajjar, A. M., O'Mahony, D. S., Ozinsky, A., Underhill, D. M., Aderem, A., Klebanoff, S. J. and Wilson, C. B. (2001). Cutting edge: Functional interaction between Toll-like receptor (TLR) 2 and TLR1 or TLR6 in response to phenol-soluble modulin. J Immunol, 166, 15-19.

[25] Morrison, L. A. (2004). The Toll of herpes simplex virus infection. Trends Microbiol, 12, 353-356.

[26] Murawski, M, R., Bowen, G. N., Cerny, A. M., Anderson, L. J., Haynes, L. M., Tripp R. A., Kurt-Jones, E. A. and Finberg, R. W. (2009). Respiratory syncytial virus activates innate immunity through Toll-like receptor 2. J Virol, 83, 1492-1500.

[27] Texereau, J., Chiche, J. D., Taylor, W., Choukroun, G., Comba, B., and Mira, J. P. (2005). The importance of Toll-like receptor 2 polymorphisms in severe infections. Clin Infect Dis, 41, 408-415.

[28] Bochud, P. Y., Magaret, A. S., Koelle, D. M., Aderem, A., and Wald, A. (2007). Polymorphisms in TLR2 are associated with increased viral shedding and lesional rate in patients with genital herpes simplex virus Type 2 infection. J Infect Dis, 196, 497-498.

[29] Amato-Almanza, M., Bautista-de Lucio V. M., Pérez-Cano, H. J. and Mejía-López, H. (2009). Polimorfismo del gen TLR2 como factor de riesgo en la infección oftálmica por adenovirus. Rev Mex Oftalmol, 83, 381-384.

[30] Rehaume, L. M. and Hancock, R.E. (2008). Neutrophil-derived defensins as modulators of innate immune function. Crit Rev Immunol, 28, 185-200.

[31] Yang, D., Chertov, O., Bykovskaia, S. N., Chen, Q., Buffo, M. J., Shogan, J., Anderson, M., Schröder, J. M., Wang, J. M., Howard, O. M. and Oppenheim, J. J. (1999). Betadefensins: Linking innate and adaptive immunity through dendritic and $\mathrm{T}$ cell CCR6. Science, 286, 525-528.

[32] Harvey, S. A., Romanowski, E. G., Yates, K. A. and Gordon, Y.J. (2005). Adenovirusdirected ocular innate immunity: The role of conjunctival defensin-like chemokines (IP-10, I-TAC) and phagocytic human defensin-alpha. Invest Ophthalmol Vis Sci, 46, 3657-3665.

[33] Li, J., Raghunath, M., Tan, D., Lareu, R. R., Chen, Z. and Beuerman, R. W. (2006). Defensins HNP1 and HBD2 stimulation of wound-associated responses in human conjunctival fibroblasts. Invest Ophthalmol Vis Sci, 47, 3811-3819.

[34] Milanese, M., Segat, L. and Crovella, S. (2007). Transcriptional effect of DEFB1 gene 5' untranslated region polymorphisms. Cancer Res, 67, 5997.

[35] Sun, C. Q, Arnold, R., Fernandez, C., Parrish, A. B., Almekinder, T., He, J., Ho, S. M., Svoboda, P., Pohl, J., Marshall, F. F. and Petros, J. A. (2006). Human beta-defensin- 
1, a potential chromosome $8 \mathrm{p}$ tumor suppressor: Control of transcription and induction of apoptosis in renal cell carcinoma. Cancer Res, 66, 8542-8549.

[36] Tesse, R., Cardinale, F., Santostasi, T., Polizzi, A., Manca, A., Mappa, L., Lacoviello, G., De Robertis, F., Logrillo, V. P. and Armenio, L. (2008). Association of beta-defensin1 gene polymorphisms with Pseudomonas aeruginosa airway colonization in cystic fibrosis. Genes Immun, 9, 57-60.

[37] Braida, L., Boniotto, M., Pontillo, A., Tovo, P. A., Amoroso, A. and Crovella, S. (2004). A single-nucleotide polymorphism in the human beta-defensin 1 gene is associated with HIV-1 infection in Italian children. AIDS, 18, 1598-1600.

[38] Milanese, M., Segat, L., Pontillo, A., Arraes, L. C., De Lima Filho, J. L. and Crovella, S. (2006). DEFB1 gene polymorphisms and increased risk of HIV-1 infection in Brazilian children. AIDS, 20, 1673-1675.

[39] Jurevic, R. J., Bai, M., Chadwick, R. B., White, T. C. and Dale, B. A. (2003). Singlenucleotide polymorphisms (SNPs) in human beta-defensin 1: High-throughput SNP assays and association with Candida carriage in type I diabetics and nondiabetic controls. J Clin Microbiol, 41, 90-96.

[40] Carter, J. G., West, S. K., Painter, S., Haynes, R. J. and Churchill, A. J. (2009). BetaDefensin 1 haplotype associated with postoperative endophthalmitis. Acta Ophthalmol, 88, 786-790.

[41] Crum, N. F, Barrozo C. P., Chapman,F. A. , Ryan, M. A. and Russell, K. L. (2004). An outbreak of conjunctivitis due to a novel unencapsulated Streptococcus pneumoniae among military trainees. Clin Infect Dis, 39, 1148-1154.

[42] Martin, M., Turco, J. H., Zegans, M. E., Facklam, R. R., Sodha, S., Elliott, J.A., Pryor, J. H., Beall, B., Erdman, D. D., Baumgartner, Y. Y., Sanchez, P. A., Schwartzman, J. D., Montero, J., Schuchat, A. and Whitney, C. G. (2003). An outbreak of conjunctivitis due to atypical Streptococcus pneumoniae. N Engl J Med, 348, 1112-1121.

[43] Buznach, N., Dagan, R. and Greenberg, D. (2005). Clinical and bacterial characteristics of acute bacterial conjunctivitis in children in the antibiotic resistance era. Pediatr Infect Dis J, 24, 823-828.

[44] Mikru, F.S., Molla, T., Ersumo, M., Henriksen, T. H., Klungseyr, P., Hudson, P.J. and Kindan T. T. (1991). Community-wide outbreak of Neisseria gonorrhoeae conjunctivitis in Konso district, North Omo administrative region. Ethiop Med J, 29, 27-35.

[45] Mak, D. B., Smith, D. W., Harnett, G. B. and Plant A. J. (2001). A large outbreak of conjunctivitis caused by a single genotype of Neisseria gonorrhoeae distinct from those causing genital tract infections. Epidemio Infect, 126, 373-378.

[46] Kakar, S., Bhalla, P., Maria, A., Rana, M., Chawla, R. and Mathur, N. B. (2010). Chlamydia trachomatis causing neonatal conjunctivitis in a tertiary care center. Indian J Med Microbiol, 28, 45-47.

[47] Krasny, J., Tomasova-Borovanska, J. and Hruba D. (2005). The Relationship between Chlamydia trachomatis and Chlamydia pneumoniae as the cause of neonatal conjunctivitis (ophthalmia neonatorum). Ophthalmologica, 219, 232-236.

[48] Thylefors, C., Dawson, C. R., Jones, B. R., West, S. K. and Taylor, H. R. (1987). A simple system for the assessment of trachoma and its complications. Bull World Health Organ, 65, 477- 483. 
[49] Burton, M.J. and Mabey, D. C. W. (2009). The global burden of trachoma: A Review. PloS Negl Trop Dis, 3(10): e460.

[50] Dean, D., Kandel, R. P., Adhikari, H. K. and Hessel, T. (2008). Multiple Chlamydiaceae species in trachoma: implications for disease dathogenesis and control. PLoS Med, 5(1/e14):0057-0068.

[51] Cooper, R. J., Yeo, A. C., Bailey, A.S. and Tullo, A. B. (1999). Adenovirus polymerase chain reaction assay for rapid diagnosis of conjunctivitis. Invest Ophthalmol Vis Sci, 40, 90-95.

[52] Horwitz, M. S. (1996). Adenoviruses Chapter 68. In: Fields BN, Knipe DM, Howley, PM, et al. Fields Virology. Third Ed. Lippincott Raven Publishers Philadelphia p 2149.

[53] Shepetiuk, S. K., Norton, R., Kok, T. and Irving, L. G. (1999). Outbreak of adenovirus type 4 conjunctivitis in South Australia. J Med Virol, 41, 316-318.

[54] Jernigan, J. A., Lowry, B. S., Hayden, F. G., Kyger, S. A., Conway, B. P., Gröschel, D. H. M. and Farr, B. M. (1993). Adenovirus type 8 epidemic keratoconjunctivitis in an eye clinic: risk factor and control. J Infect Dis, 167, 1307-1313.

[55] Takeuchi, S., Itoh, N., Uchio, E., Tanaka, K., Kitamura, N., Kanai, H., Isobe, K., Aoki, K. and Ohno, S. (1999). Adenovirus strain of subgenus D associated with nosocomial infection as new etiological agents of epidemic keratoconjunctivitis in Japan. J Clin Microbiol, 37, 3392-3394.

[56] Belongia, E. A., Goodman, J. L., Holland, E. J., Andres, C. W., Homann, S. R., Mahanti, R. L., Mizener, M. W., Erice, A. and Osterholm, M.T. (1991). An outbreak of herpes gladiatorum at a high-school wrestling camp. N Engl J Med, 325, 906-910.

[57] Aoki, K. and Sawada, H. (1992). Long-term observation of neutralization antibody after enterovirus 70 infection. Jpn J Ophthalmol, 36, 465-468.

[58] Jun, E. J., Won, M. A., Ahn, J., Ko A., Moon, H., Tchah, H., Kim, Y. K. and Lee, H. (2011). An antiviral small-interfering RNA simultaneously effective against the most prevalent enteroviruses causing acute hemorrhagic conjunctivitis. Invest Ophthalmol, Vis Sci, 52, 58-63.

[59] Langford. M.P., Ball, W. A. and Ganley, J. P. (1995). Inhibition of the enteroviruses that cause acute hemorrhagic conjunctivitis (AHC) by benzimidazoles, enviroxime (LY 122772) and enviradone (LY 127123). Antiviral Res, 27, 355-365.

[60] Nigrovic, L. E. and Chiang, V. W. (2000). Cost analysis of enteroviral polymerase chain reaction in infants with fever and cerebrospinal fluid pleocytosis. Arch Pediatr Adolesc Med, 154, 817-821.

[61] Xiao, X. L., Wu, H., Li, Y. J., Li, H. F., He, Y. Q., Chen, G., Zhang, J. W., Yang, H., Li, X. F., Yang, X. Q. and Yu, Y. G. (2009). Simultaneous detection of enterovirus 70 and coxsackievirus A24 variant by multiplex real-time RT-PCR using an internal control. J Virol Meth, 159, 23-28. 


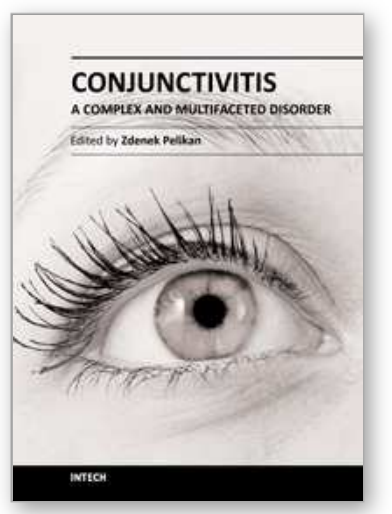

\author{
Conjunctivitis - A Complex and Multifaceted Disorder \\ Edited by Prof. Zdenek Pelikan
}

ISBN 978-953-307-750-5

Hard cover, 232 pages

Publisher InTech

Published online 23, November, 2011

Published in print edition November, 2011

This book presents a number of interesting and useful aspects and facets concerning the clinical features, properties and therapeutical management of this condition. Dr. H. Mejía-López et al. present an interesting survey of the world-wide epidemiologic aspects of infectious conjunctivitis. Dr. U. Ubani evaluates conjunctival symptoms/signs participating in the clinical features of this disorder. Dr. A. Robles-Contreras et al. discuss immunologic aspects underlying possibly the conjunctivitis. Dr. Z. Pelikan presents the cytologic and concentration changes of some mediators and cytokines in the tears accompanying the secondary conjunctival response induced by the nasal challenge with allergen. Dr. S. Sahoo et al. summarize the treatment and pharmacologic control of particular clinical forms of conjunctivitis in general practice. Dr. S. Leonardi et al. explain the basic pharmacologic effects of leukotriene antagonists and their use for the treatment of allergic conjunctivitis. Dr. J.A. Capriotti et al. evaluate the therapeutical effects of various anti-adenoviral agents on the acute conjunctivitis caused by adenovirus. Dr. V. Vanzzini-Zago et al. assess the prophylactic use and efficacy of "povidone-iodium solution", prior the ocular surgery. Dr. F. Abazi et al. present the clinical features, diagnostic and therapeutical aspects of "neonatal conjunctivitis". Dr. I.A. Chaudhry et al. review the special sub-form of conjunctivitis, being a part of the "Trachoma". Dr. B. Kwiatkowska and Dr. M. Maślińska describe the clinical, pathophysiologic and immunologic features of conjunctivitis. Dr. S. Naem reviews the conjunctivitis form caused by Thelazia nematodes, occurring principally in animals.

\title{
How to reference
}

In order to correctly reference this scholarly work, feel free to copy and paste the following:

Herlinda Mejia-López, Carlos Alberto Pantoja-Meléndez, Alejandro Climent-Flores and Victor M. Bautista-de Lucio (2011). Epidemiological Aspects of Infectious Conjunctivitis, Conjunctivitis - A Complex and Multifaceted Disorder, Prof. Zdenek Pelikan (Ed.), ISBN: 978-953-307-750-5, InTech, Available from:

http://www.intechopen.com/books/conjunctivitis-a-complex-and-multifaceted-disorder/epidemiological-aspectsof-infectious-conjunctivitis

\section{INTECH}

open science | open minds

\section{InTech Europe}

University Campus STeP Ri

Slavka Krautzeka 83/A

51000 Rijeka, Croatia

\section{InTech China}

Unit 405, Office Block, Hotel Equatorial Shanghai

No.65, Yan An Road (West), Shanghai, 200040, China

中国上海市延安西路65号上海国际贵都大饭店办公楼405单元 
Phone: +385 (51) 770447

Fax: +385 (51) 686166

www.intechopen.com
Phone: +86-21-62489820

Fax: +86-21-62489821 
(C) 2011 The Author(s). Licensee IntechOpen. This is an open access article distributed under the terms of the Creative Commons Attribution 3.0 License, which permits unrestricted use, distribution, and reproduction in any medium, provided the original work is properly cited. 